The American Journal of Medical Sciences and Pharmaceutical Research (ISSN - 2689-1026)

VOLUME 04 ISSUE 01 Pages: 35-39

SJIF IMPACT FACTOR (2020: 5. 286) (2021: 5. 64)

OCLC - 1121105510 METADATA IF -7.569

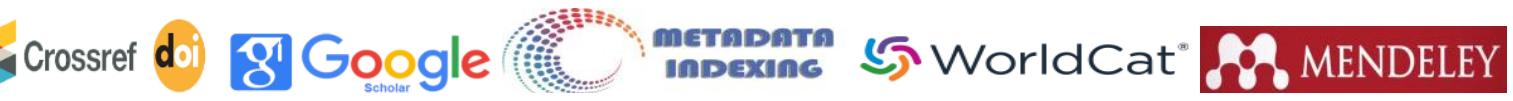

Research Article

\title{
AUTONOMIC NERVOUS SYSTEM RESEARCH INDICATORS IN THE ELDERS
}

\author{
Submission Date: January 07, 2022, Accepted Date: January 17, 2022, \\ Published Date: January 27, 2022 | \\ Crossref doi: https://doi.org/10.37547/TAJMSPR/Volume04Issue01-05 \\ Ismigul Abbosova \\ Andijan State Medical Institute, Andijan, Uzbekistan \\ Iroda Rustamova \\ Andijan State Medical Institute, Andijan, Uzbekistan
}

\section{ABSTRACT}

The publication discusses the indicators of the study of vegetative tone, vegetative reactivity and vegetative security of activity in elderly people with vegetative dystonia syndrome. 180 patients with $\mathrm{CCl}$ of the second stage were studied, the average age was 67.4 \pm 6.1 years. The patients were divided into two groups. Group I consisted of 118 patients ( $62.2 \%$ of the total number of patients) with stage 2 chronic cerebral ischemia (CCI) with ADS, group 2 consisted of 62 patients (34.4\%) with stage 2 CCI without ADS.

\section{KEYWORDS}

Autonomic nervous system, elderly, autonomic dystonia syndrome.

\section{INTRODUCTION}

The comorbidity of vegetative disorders with cerebrovascular pathology has been proven. Stroke and structural lesions of the brain lead to dissociation of functional systems and autonomic dysregulation
$[2,3]$. Autonomic dysfunction in the acute period of stroke, according to some authors, is an unfavorable sign and indicates a poor prognosis; according to other data, this is a transient failure of adaptation [2]. 


\section{The American Journal of Medical Sciences and Pharmaceutical Research}

(ISSN - 2689-1026)

VOLUME 04 ISSUE 01 Pages: 35-39

SJIF IMPACT FACTOR (2020: 5. 286) (2021: 5. 64)

OCLC - 1121105510 METADATA IF - 7.569

\section{sone

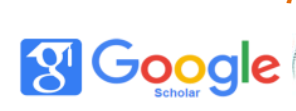

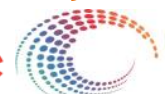

mETอDกTด

(5) WorldCat"

Publisher: The USA Journals

Cerebral ischemia activates the sympathetic-adrenal and hypothalamic-pituitary systems, as a result of which the balance of the sympathetic and parasympathetic parts of the ANS is disturbed, which can lead to severe cardiac arrhythmias, sudden cardiac arrest, stroke.

The development of vegetative disorders in patients with chronic CVD is explained by a violation of the mechanisms of autoregulation in the ANS due to hypertension and atherosclerosis: baroreflex (atherosclerosis of the carotid arteries), reflexogenic (impaired blood circulation in the vertebrobasilar system) and central mechanisms (impaired circulation of the suprasegmental structures of the ANS) [1,2 ].

Thus, the pathogenesis of the development of autonomic dysfunction in elderly patients with cerebrovascular pathology is complex and manifests itself as symptoms of damage to suprasegmental and peripheral structures, while the sympathetic nervous system is more involved. The development of autonomic disorders in patients with CVD and MS is accompanied by cardiac complications, syncope, and others, and has an unfavorable prognosis. In this regard, their timely diagnosis and treatment are extremely important.

\section{THE PURPOSE OF THE STUDY}

To identify features of autonomic nervous system parameters in elderly patients with cerebrovascular pathology.

\section{MATERIAL AND METHODS}

The clinical part of the work was carried out in the advisory polyclinic of ASMI in the period from 2019 to 2022. 180 patients with $\mathrm{CCl}$ of the second stage were under observation. The patients included 62 (37.8\%) men and $118(62.2 \%)$ women. The age of the patients ranged from 60 to 75 years, the average age was $67.4 \pm 6.1$ years.

Group I consisted of 118 patients (62.2\% of the total number of patients) with stage 2 chronic cerebral ischemia (CCl) with ADS ( 42 men (35.6\%) and 76 women $(64.4 \%))$, group 2 consisted 62 patients (34.4\%) with stage $2 \mathrm{CCl}$ without ADS (26 men (41.9\%) and 36 women (58.1\%)).

To study the presence of ADS in patients, the questionnaire of A.M. Wayne (1987). The initial vegetative tone (IVT) was determined using the table A.M. Wayne et al. [1981], which recorded clinical, electrophysiological and laboratory parameters. To assess autonomic reactivity (VR), a clino-orthostatic test (COP) is performed. Studying the clinical features of headache (HA) using the original HA questionnaire. The presence of depression was detected using the HADS scale. Patients also underwent ECG studies and ambulatory blood pressure monitoring (ABPM).

The research materials were subjected to statistical processing using the methods of parametric and nonparametric analysis. Accumulation, correction, systematization of initial information and visualization of the obtained results were carried out in Microsoft Office Excel 2016 spreadsheets. Statistical analysis was carried out using the IBM SPSS Statistics V.23 program (developed by IBM Corporation).

\section{RESEARCH RESULTS}

The majority of patients in both groups had a permanent course of ADS (82.4\%). Paroxysmal vegetative states were observed in both groups. Among patients with ADS, autonomic paroxysms in history were in 32/118 (27.1\%) people, and panic attacks in $17 / 118$ (14.4\%). In the group without ADS, the presence of vegetative crises was noted in $7 / 62$ (11.3\%) 


\section{The American Journal of Medical Sciences and Pharmaceutical Research}

(ISSN - 2689-1026)

VOLUME 04 ISSUE 01 Pages: 35-39

SJIF IMPACT FACTOR (2020: 5. 286) (2021: 5. 64)

OCLC - 1121105510 METADATA IF - 7.569

\section{Crossref dol gi Google}

resp.), supraventricular extrasystole $(28.4 \%$ and $13.4 \%$ resp.).

Numerous gastroenterological manifestations in ADS in the vast majority of cases ( $82 \%$ ) were manifested by esophageal dyskinesia (32\% in group II and $42.4 \%$ in group I), duodenogastric reflux $(24.6 \%$ and $26 \%$ respectively), intestinal dyskinesia ( $18.2 \%$ and $18 \%$, respectively), dysfunction of the hepatobiliary tract with signs of cholestasis (32\% and 38\%, respectively).

According to the Wayne questionnaire in group I, the average total score is above the norm in most patients (in $94 \%$ of cases), and the average in the group was $35 \pm 16$, which was comparable to group II. Thus, in patients without ADS, signs of autonomic dysfunction were observed in $75 \%$ of the examined patients, the average score was $38 \pm 17$.

With vagotonia in group I, endocrine pathology $(p<0.05)$, functional disorders of the gastrointestinal tract were detected 3.7 times more often. Analysis of the structure of concomitant neurological pathology revealed that in group I, markers of more severe neurological disorders were detected 2.8 times more often, such as hypodynamic states (4.3 times), depression ( 1.5 times more often) $(p<0,05)$.

Manifestations of sympathetic activation with an increase in systolic blood pressure, mean blood pressure and increased heart rate according to ABPM were noted significantly in patients with ADS (table 1 ).

I and $6.2 \%$ in group II) and the ST segment (8.2\% and $4.2 \%$ respectively), sinus arrhythmia (32\% and $22.4 \%$ 
The American Journal of Medical Sciences and Pharmaceutical Research (ISSN - 2689-1026)

VOLUME 04 ISSUE 01 Pages: 35-39

SJIF IMPACT FACTOR (2020: 5. 286) (2021: 5. 64)

OCLC - 1121105510 METADATA IF -7.569

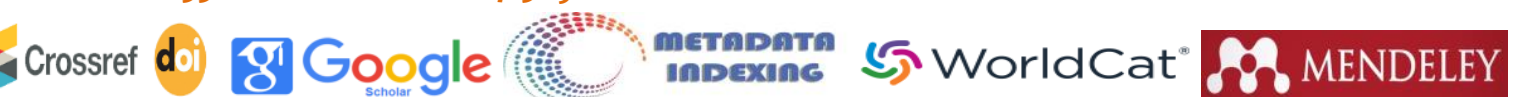

Table 1

Blood pressure level and pulse rate in groups (ABPM)

\begin{tabular}{|c|r|r|}
\hline Indicators & Group 1 & \multicolumn{1}{c|}{ Group 1 } \\
\hline Maximum SBP (mm Hg) & $163,2 \pm 28,4$ & $157,3 \pm 15,1^{*}$ \\
\hline Maximum DBP (mm Hg) & $105,7 \pm 17,1$ & $101,6 \pm 18,2$ \\
\hline Average blood pressure (mm.Hg.st) & $90,5 \pm 9,3$ & $86,7 \pm 8,4^{*}$ \\
\hline Pulse rate (bpm) & $66,8 \pm 9,2$ & $60,8 \pm 10,5^{*}$ \\
\hline
\end{tabular}

Note: * - significance of differences, $\mathrm{p}<0.05$

In group I, psycho-emotional disorders were often observed in the form of dysphoria, irritability, demonstrative behavior, a decrease in the level of attention and faster exhaustion when performing a task. When objectifying psycho-emotional disorders using the HADS scale, in group I, among patients with
$\mathrm{CCl}$, persons with clinically pronounced depression significantly predominated (score > 11), and, on average, in the group, the average score for testing the level of depression was higher compared to patients without ADS $(p<0.05)$ (table 2$)$.

Table 2

Psycho-emotional disorders (according to the HADS scale)

\begin{tabular}{|c|c|c|}
\hline HADS & Group 1 & Group 1 \\
\hline HADS anxiety score & $6,8 \pm 4$ & $6,8 \pm 3,8$ \\
\hline HADS depression, score & - $7,5 \pm 3,7 *$ & $6,5 \pm 3,8$ \\
\hline
\end{tabular}

Note: * - significance of differences, $\mathrm{p}<0.05$

Psycho-emotional and vegetative disorders in the ADS group correlated with metabolic parameters. Thus, the presence of depression on the HADS scale significantly correlated with an increase in body mass index $(r=$ $0.41, p<0.05)$, an increase in waist circumference $(r=$ $0.36)$, a level of glycated hemoglobin $(r=0.26)$ and duration arterial hypertension ( $r=0.32)$, as well as the total score on the autonomic change questionnaire ( $r$ $=0.57$ ).

The result of testing on the questionnaire of vegetative changes had a direct relationship with the degree of $\mathrm{AH}(r=0.54)$ and blood glucose level $(r=0.54)$ in the MS group. In the group without ADS, there was a positive correlation between the score of autonomic 


\section{The American Journal of Medical Sciences and Pharmaceutical Research}

(ISSN - 2689-1026)

VOLUME 04 ISSUE 01 Pages: 35-39

SJIF IMPACT FACTOR (2020: 5. 286) (2021: 5. 64)

OCLC - 1121105510 METADATA IF - 7.569

\section{Crossref dol gु' Google}

4. Khasanov, A. (2016). About several

disorders and the level of anxiety on the HADS scale ( $r$ $=0.49)$ and the degree of $\mathrm{AH}(\mathrm{r}=0.45)$ at $\mathrm{p}<0.05$.

It was found that the activity of psychosomatic complaints positively correlated with the average anxiety score ( $\mathrm{rij}=+0.41, \mathrm{p}<0.05)$. Based on the results of a survey and examination of patients, a group of somatic symptoms was identified that most often correlated with psychosomatic distress, depression and anxiety: headache (rij=+0.5, p<0.05), abdominal pain (rij =+0.6, p<0.05), fatigue ( $\mathrm{rij}=+0.3, \mathrm{p}<0.05$ ), increased heart rate ( $\mathrm{rij}=+0.4, \mathrm{p}<0.05)$, "unsatisfied breath" ( $\mathrm{rij}=+0.3, \mathrm{p}<0.05)$. Together, they represent a somatovegetative symptom complex that aggravates the course of the underlying chronic disease.

\section{CONCLUSION}

The combination of psycho-vegetative and somatic manifestations, accompanied by constant emotional stress, is a reliable diagnostic sign that allows assessing the severity of the progression of cerebrovascular pathology in the elderly. Time to take preventive measures to eliminate a poor prognosis.

\section{REFERENCES}

1. Nalbat A.V., Yakupov E.Z., Khuzyasheva E.I. Syndrome of autonomic dysfunction in various forms of vascular pathology of the brain /I Neurological Bulletin. - 2012. - No. 44(3). P.100108.

2. Skoromets A.A. Somatoneurology: a guide for physicians. - St. Petersburg: SpecLit, 2009.

3. Fonyakin A.V., Samokhvalova E.V., Geraskina L.A. Autonomic regulation of the heart and the risk of cardiac complications in ischemic stroke. Praktichna angiology. - 2008. - № 5(16). - P. 26-30. infrastructure constructions of the Great Silk Road. Int'l J Innov Sci Eng Technol, 3(6), 295299.

5. Inogamov, B. I., \& Khasanov, A. O. (2021). Taking Into Account Socio-Functional Factors in the Design of Housing. Design Engineering, 2587-2589.

6. Kurtieva, S., Nazarova, J., \& Mullajonov, H. (2021). Features of Physical and Generative Development of Modern Teenagers Living in Uzbekistan. NeuroQuantology, 19(7), 57.

7. Zukhritdinova, D., \& Nazarova, J. (2021). Clinical Structure of Headache Syndrome in Adolescents with Autonomic Dystonia Syndrome. European Journal of Molecular \& Clinical Medicine, 7(11), 4487-4493. 